vulcanite four inches in diameter and one-eighth of an inch in thickness, connected by a rivet which allows one to slide over the other. A V-shaped notch is cut from the circumference to the centre of each disc, but in opposite directions, so that they form together an opening large enough for the penis. By sliding one disc over the other, the opening is contracted, and when the penis is sufficientiy compressed to stop the passage of blood, a binding-screw fixes the clamp.

I used to tie the penis with a piece of cord or red tape, and protect the pubes from any drops of blood by a piece of waterproof with a hole in it, but about six years ago it occurred to me that the instrument I have described would act both as the most convenient form of tourniquet and sufficiently protect the pubes, and on making use of it I found that it had the further advantage of retaining the penis in a position convenient for the surgeon.

Whilst writing on this subject, let me recommend a method of applying sutures suitable in all cases where the skin is very thin and abundant, but especially after the circumcision of boys. The plan is to use a glover's needle and fine waxed silk, and puncture as near as possible to the cut edge, and then draw the suture as tightly as if tying an artery. There is no need to tie the second half of the reefknot. The skin will give way sooner than the knot. These sutures come away in removing the dressing on the second or third day, without any need of using scissors or forceps -instruments that are regarded with terror at these times. $I$ have often been called to give chloroform whilst the surgeon removed the sutures from a circumcised penis, he having been unable to keep the patient sufficiently steady without it. In order to pierce the skin so near to the edge it must be held with forceps, and if they have a notch at the points the skin is held so steadily that a common sewing-needle may be used.

I am, Sir, your obedient servant

Carendish-place, $\mathrm{W}$. J. T. CLOVER,

\section{THE CONSTITUTION OF THE GENERAL MEDICAL COUNCIL.}

To the Editor of THE LANCET.

SIR,-In a recent number you pointed out, as a defect in the constitution of the General Medical Council, the small proportion of surgeons, the Crown's four nominees being all physicians. It is not my purpose to refer to this defect further than to observe that the Colleges of Surgeons are represented by surgeons elected by their governing bodies. A far more serious defect is the utter want of representation of the obstetric department of medicine. After many years' work of the Medical Council, the state of obstetric practice in this country still remains in the same discreditable, because discredited, and chaotic condition as ever. Little or rather no security exists for providing the mass of the people with competent practitioners of midwifery. The conditions under which this branch of medicine is taught in our schools, and the position which it holds in the examinations for diplomas, are in the last degree unsatisfactory.

It is hardly reasonable to expect that a subject which demands special and wide acquaintance should be fairly dealt with by physicians and surgeons, who for the most part know little and care less about it. The constitution of the governing-that is, the electing-bodies is such that obstetric practitioners have no voice in the election. The whole power of the Colleges is monopolised by the pure physicians and surgeons, leaving the great bulk of the professionthat is, the members and licentiates of the Colleges-unrepresented.

That this state of things is fraught with danger to the public, that it impairs the confidence of the profession in the action of the Medical Council, and that it is the cause of much of the dissatisfaction which that body has inspired, no impartial looker-on can doubt.

The immediate remedy rests with the Crown, which has the privilege of selecting from a wider and more popular field than the small councils or other elective bodies of the universities and colleges. This privilege, if wisely exercised, gives the much-needed opportunity of correcting any errors which the universities and colleges, naturally reflecting their own faults as well as their virtues, can hardly fail to commit. This privilege, indeed, seems expressly reserved for the purpose of restoring the proper balance of representation by supplying elements ignored by the elective bodies.

I am, Sir, yours, \&c.

An Obstemric Teacher and Practitioner.

Norember, 1873.

\section{THE ASHANTEE WAR: AN EXPLANATION.}

To the Editor of THE LANCET.

Srr,-Your brief notice of the Army Hospital Corps last week contains a misapprehension of my letter to The Times, which I hope you will kindly permit me to remove. I was perfectly aware of the special training in field duties to which the corps above mentioned is subjected at Netley, and did not consider that a fact so well known needed special mention.

What I referred to was, in my humble judgment, a far more important matter-viz., special instruction by the professors of hygiene and medicine in the best means of preventing, so far as it is preventable, the serious sickness almost certain to be encountered in military operations on so pestilential a field as the Gold Coast.

It seems to me that one of the proper functions of a great military medical school should be to consider the medical aspect of any war in which this country is likely to be engaged or to which it is committed. To study it specially and to afford special instruction regarding it would be the natural result of such study. These are some matters connected with the protection of the soldier against disease in the field which are not to be found in books, even if books could be carried and consulted on a campaign. The soldier himself is proverbially careless in such matters; hence to be forewarned is to be forearmed. Injuries on the field of battle from so badly-armed an enemy as the Ashantees will probably play an unimportant part in the approaching field operations. Not so the sun-strokes, fevers, dysentery, and similar contingencies of fighting in an African bush and under an African sun. The value of authoritative instructions on such probable incidents of the Ashantee War from so eminent a body as the medical staff at Netley could scarcely be over-estimated. This is what I intended to express in my letter to The Times.

November 3rd, 1873 I am, Sir, yours faithfully,

\section{URETHROTOMY OR LITHOTRITY IN AGED AND DEBILITATED PEOPLE.}

\section{To the Editor of THE LANCET.}

SrR,-I have read with interest an article on the above subject, by Mr. Crowther, in your journal of Saturday last; but inasmuch as the kind of operation practised by himself and others is founded on a principle which is not supported by facts, a few remarks are called for. At page 624 he thus explains his method:- "I mean urethrotomy by the median section, with simple dilatation by the finger of the prostate gland." Now Professor Ellis has, years ago, shown that the prostate could not be dilated, and I would recommend any surgeon who has a doubt on the point to attend his incontrovertible demonstration on the subject. To say more would almost seem superfluous, but it may not perhaps be remembered that the prostate gland is encased in two jackets of white fibrous tissue, so dense and strong that the capsule is described, in Quain and Sharpey's Anatomy, fifth edition, page 1216, as "rather difficult eit her to tear or cut" ; and yet this coat enveloping the prostate is supposed by many surgeons to stretch like a piece of india-rubber to kindly allow them to take out the stone and then to quietly return to its pristine condition. But facts prove that the prostate has never dilated for any surgeon, for it has only given way when lacerated or cut. Why has Dolbea introduced perineal lithotrity? Simply because he found, by experiment on the dead subject, that the prostatic urethra could not be dilated beyond twenty millimetres, which is about its normal diameter in old men. The experiments which I myself performed in reference to the 